\title{
Stress and cancer surveys: attitudes of participants in a case-control study
}

\author{
Cynthia Taylor, Pamela Trowbridge, Clair Chilvers
}

Section of Epidemiology, Institute of Cancer Research, Block D, 15 Cotswold Road, Belmont, Surrey, United Kingdom C Taylor

P Trowbridge

C Chilvers

Correspondence to: Professor Chilvers, at Department of Public Health Medicine and Epidemiology, Queen's Medical Centre, University of Nottingham, Nottingham NG7 2UH, United

Kingdom

Accepted for publication November 1990

\begin{abstract}
Study objective-The aim was to ascertain whether personal interviews carried out for cancer case-control studies cause stress to participants.
\end{abstract}

Design-Retrospective postal questionnaires were sent to women at least three months after interview for a case-control study of the aetiology of cervical cancer. The questionnaire covered attitudes to taking part in the study, stress engendered by participation, whether any particular questions were distressing, factors relevant to the decision to participate, and the role of their doctor with respect to participation.

Setting-South East and South West Thames health regions, United Kingdom.

Patients-Patients were women aged $20-45$ years at diagnosis with invasive cervical cancer, and population based controls.

Measurements and main results-The response rate was $90 \%$. Nearly all respondents were glad they had participated, while only $2 / 226$ regretted taking part. Half the respondents (115/226) perceived some actual benefit from taking part. The interview carried out in the casecontrol study was both long and detailed and included topics such as numbers of sexual partners and history of sexually transmitted diseases. As expected, the questions causing most concern to interviewees were those on number of sexual partners, but only $13 \%$ of participants were bothered by these questions and only $4 \%$ felt inclined to terminate the interview early.

Conclusions-The lack of evidence of stress caused by this potentially difficult interview suggests that, in the hands of experienced interviewers, stress is unlikely to be caused by participation. Many participants felt that they had benefited from taking part. Doctors and ethics committees should find these results reassuring.

It has been suggested that healthy controls may be subjected to stress when they are included in a "cancer survey". ${ }^{1}$ This suggestion does not seem to be corroborated by studies carried out in the $\mathrm{USA}^{23}$ and we have been unable to find any relevant study carried out in the United Kingdom. Increasing numbers of case-control studies requiring a personal interview are being conducted, and doctors and ethics committees frequently express concern about the effect of participation on both patients (cases) and healthy controls. In studies of cancer aetiology, in young people in particular, population based controls rather than hospital inpatient controls are often required. We are carrying out a series of population based case-control studies involving a personal interview; we used one of these studies as an opportunity to investigate the effect of participation on respondents and ways in which our procedure for approaching participants might be made more acceptable.

The principal aims of our study were to investigate why women agreed to take part in a case-control study of the aetiology of cervical cancer, how they were affected by the interview, whether sufficient information was given to them prior to interview, and what was perceived by them as the purpose of the study.

\section{Methods}

The women included in this survey were a sample of those who had been interviewed as part of a multicentre case-control study of cervical cancer carried out by the Institute of Cancer Research, the Imperial Cancer Research Fund, and Oxford University. In the original study, cases had been identified through the cancer registration system; permission to contact each case for the original interview was obtained both from the consultants who treated her and from her general practitioner. One or more age matched controls for each case were selected from the same general practitioner's list. All cases and controls were intitially contacted by letter from the Department of Community Medicine and General Practice, University of Oxford, and asked to participate in a study of the causes of disease of the cervix. The word "cancer" was not used in the original letter because some ethics committees would not agree to it, and we also were unsure as to whether the mention of cancer might cause anxiety. We were careful to reassure control women that they had been selected at random as a healthy control for someone who was ill.

The original interviews had been conducted mainly in the interviewees' homes, a few in doctors' surgeries, and lasted for approximately one hour. Topics covered by the interview included obstetric and sexual history, use of oral contraceptives, and history of cervical smears. Permission to abstract information from general practitioner and family planning clinic notes was sought. The interview was usually followed by further contact, generally by telephone, to reconcile conflicting information obtained from general practitioner notes or family planning clinics. 
A post-interview questionnaire was sent to the first 127 cases and 125 controls interviewed in the South East Thames and South West Thames regions. The post-interview questionnaire was mainly derived from that used by Savitz $e t a l^{3}$ which incorporated parts of that of Funch and Marshall. ${ }^{2}$ It included both closed and open questions and took approximately 15 minutes to complete. It was sent out three months after interview or one month after all queries arising from the interview had been settled, whichever was the later.

If the completed questionnaire had not been received within one month, a telephone call was made to encourage the interviewee to return it. Those non-responders who were not on the telephone were sent a second questionnaire. Occasionally individual questions were not answered. Where appropriate, a question not answered was assumed to have the answer "No". $\chi^{2}$ Tests for differences in proportions were carried out to test for different responses in cases and controls.

Table I Factors influencing decision to agree to interview, by disease status. Number (per cent).

\begin{tabular}{|c|c|c|c|}
\hline & $\begin{array}{l}\text { Cases } \\
(n=110)\end{array}$ & $\begin{array}{l}\text { Controls } \\
(n=116)\end{array}$ & $\begin{array}{l}\text { Total } \\
(n=226)\end{array}$ \\
\hline $\begin{array}{l}\text { Factors encouraging participation: } \\
\text { Study importance } \\
\text { Family attitudes to participation }{ }^{\mathrm{a}} \text { : }\end{array}$ & $108(98)$ & $114(98)$ & $222(98)$ \\
\hline $\begin{array}{l}\text { for } \\
\text { indifferent } \\
\text { against } \\
\text { Health experiences } \\
\text { Involvement of University of Oxford } \\
\text { Could not justify refusal } \\
\text { Conversation with interviewer } \\
\text { Wish to help fight disease } \\
\text { Curiosity }\end{array}$ & $\begin{aligned} & 69(71) \\
& 22(23) \\
& 6(6) \\
& 63(57) \\
& 29(26) \\
& 26(24) \\
& 20(18) \\
& 8(7) \\
& 0\end{aligned}$ & $\begin{aligned} & 58(57)^{\star} \\
& 40(39) \\
& 4(4) \\
& 27(23)^{\star} \\
& 27(23) \\
& 30(26) \\
& 14(12) \\
& 11(9) \\
& 1(1)\end{aligned}$ & $\begin{aligned} 127(64) \\
62(31) \\
10(5) \\
90(40) \\
56(25) \\
56(25) \\
34(15) \\
18(8) \\
1(<1)\end{aligned}$ \\
\hline $\begin{array}{l}\text { Factors causing concern about interview: } \\
\text { Providing personal information } \\
\text { Allowing stranger into home } \\
\text { Accuracy of memory } \\
\text { Taking up time } \\
\text { Family } \\
\text { Reliving a difficult time }{ }^{b} \\
\text { Conversation with interviewer }\end{array}$ & $\begin{array}{cc}53 & (48) \\
12 & (11) \\
14 & (13) \\
6 & (5) \\
6 & (5) \\
6 & (5) \\
0 & \end{array}$ & $\begin{array}{rr}64 & (55) \\
20 & (17) \\
9 & (8) \\
11 & (9) \\
4 & (3) \\
3 & (3) \\
1 & (1)\end{array}$ & $\begin{array}{rr}117 & (52) \\
32 & (14) \\
23 & (10) \\
17 & (8) \\
10 & (4) \\
9 & (4) \\
1 & (<1)\end{array}$ \\
\hline
\end{tabular}

apercentages quoted are of those who had consulted their families.

Responses specified by the respondent.

${ }^{\star} \chi{ }^{2}$ for differences between cases and controls, $\mathrm{p}<0.05$

Table II Respondents attitudes to the interview and views of general practitioner consent, by disease status. Number (per cent).

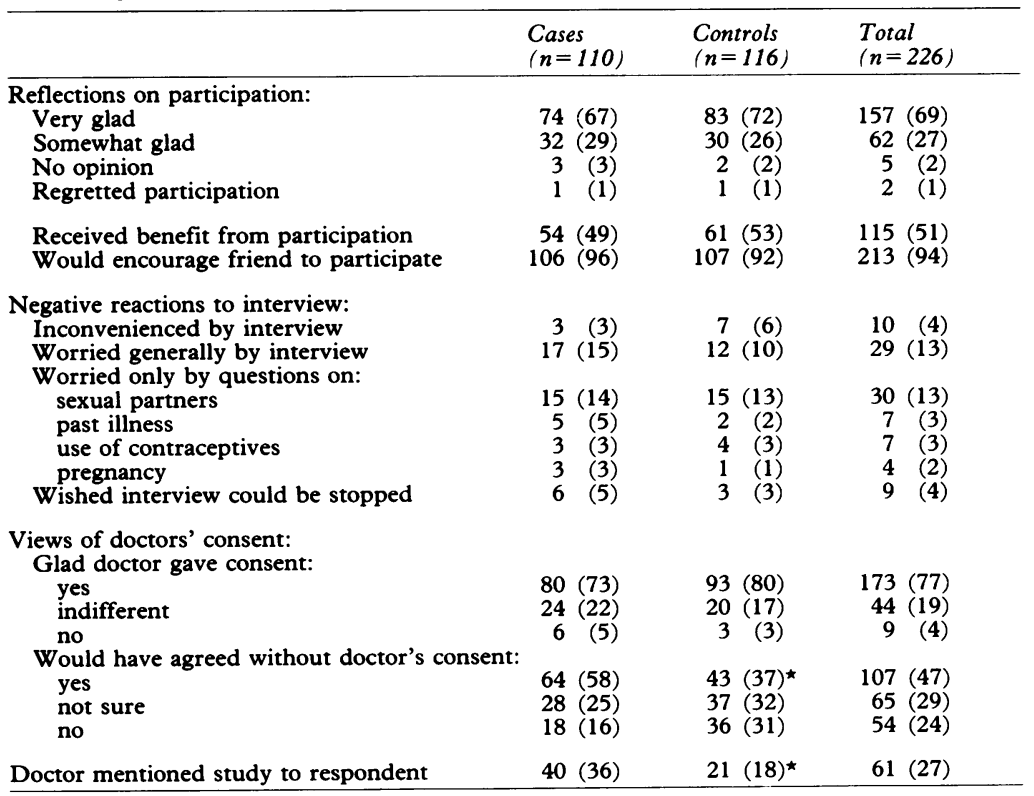

${ }^{\star} \chi^{2}$ for differences between cases and controls, $p<0.05$.

\section{Results}

Of 252 questionnaires (127 cases, 125 controls) sent out, $226\left(90^{\circ}\right)$ were returned, $110\left(87^{\circ}{ }_{0}\right)$ from cases and $116\left(93^{\circ} \%\right)$ from controls. We were unable to contact eight interviewees.

Factors that may have influenced the decision as to whether to participate in the case-control study are shown in table I. Responses were elicited by means of closed questions but with a final "other" category to be specified by the respondent. The responses in this latter category are indicated in the table. With the exception of two cases and two controls all respondents felt the study to be important. Sixty-four per cent of the 199 interviewees who had consulted their families were positively encouraged to participate, while only 10 women reported that their families were actively against their participation. Significantly more cases than controls cited their own recent health experiences or those of others close to them as a factor encouraging response $(p<0.05)$. Of the other reasons suggested in the questionnaire as encouraging participation, the involvement of the University of Oxford and conversation with the interviewer prior to the interview were positive influences. Other reasons given for participation were the duty felt by health care professionals included in the study and a wish to help research.

The factor most often cited as discouraging participation was worry about the disclosure of personal information. Other factors were cited much less often. Again, closed questions were used, with an "other" category. The responses from the latter category are again specified in table I; worry about accuracy of memory was particularly important to respondents.

Respondents' attitudes to interview are shown in table II; all in response to closed questions. In answer to the question "How did you feel about the study?", the vast majority of respondents $(97 \%)$ were "very glad" or "somewhat glad" that they had participated. Overall attitudes of cases and controls to participation were similar. However, of those who had considered refusing, only $41 \%(17 / 41)$ were "very glad' to have participated compared with $76^{\circ} \%(140 / 185)$ of those who had not considered refusing $(p<0.001)$. Fifty one per cent of respondents claimed to have received some benefit from taking part in the study, most in the satisfaction they felt from having helped others or themselves by participation in research directed towards the prevention or cure of cancer. Eight per cent of respondents found it helpful to talk to someone about their problems or their worries and $8^{\circ}$ of felt that they had learned something from taking part.

We asked whether or not they would advise a friend to take part in such a survey. Of 13 respondents who would not positively advise taking part only two were definitely against; one (case) was, however, "somewhat glad" to have taken part herself while the other (control) wished that she had not done so.

There were few negative reactions to the interview (table II). Only $4 \%$ of interviewees reported that the interview had caused them inconvenience. Thirteen per cent responded positively to the question "Were you bothered by the interview in any way?", but of these, 14 were concerned by the difficulty in remembering dates 
or facts. Eight respondents felt embarrassment and six disliked talking about past or present experiences. Other respondents, while not worried by the interview overall, found particular questions difficult. Specific questions were asked about pregnancies, past illnesses and operations, sexual partners, and contraception; for example, "Did you mind answering questions related to pregnancies?". The section causing most problems was that concerning sexual partners, even so mentioned by only 30 interviewees. The questions on pregnancies, past illness and contraception caused concern to few interviewees. Only nine respondents indicated that they had wished at some point to stop the interview. In response to an open question, reasons for wishing to stop included embarrassment at the personal nature of the questions (four respondents), a wish to sort out their memory (two respondents), and reluctance to talk about cancer (one respondent, although cancer was not mentioned explicitly in the course of the interview). Of these nine respondents, two wished that they had not taken part. In the section asking for general comments, one case recorded that although she was glad to have taken part, her husband had been upset by her participation.

The response to the question "Was it easier to talk with the interviewer than you expected, or was it more difficult?" indicated that the anticipation of the interview was generally worse than it was in practice. Sixty five per cent of respondents found talking to the interviewer easier than expected and only $2^{\circ}{ }_{0}$ found it more difficult. Less than half the respondents $\left(48^{\circ}{ }_{0}\right)$ were nervous about the interview.

Respondents' general practitioners were asked for consent before contact was made with cases and controls. Respondents' views of their doctor agreeing to this contact were mixed (table II). Overall, $4 \%$ would have preferred that their doctor had not given consent. Significantly more cases than controls would have agreed without the consent of their general practitioner $(p<0.05)$. Thirty six per cent of cases reported that their general practitioner had mentioned the study to them, compared with only $18^{\circ}{ }^{\circ}$ of controls $(p<0.05)$. Four respondents, in their genera comments about the study, mentioned specifically that they would have liked their doctor to have written to them first about the study.

Eighty four per cent of respondents felt that they had received sufficient information about the study in the initial letter, and of the 36 women who did not, seven simply felt that they could have answered the questions more accurately if they had known their content in detail beforehand.

Cervix cancer was not mentioned either in the initial letter or during the interview. The letter did mention "disease of the cervix (neck of the womb)". Of the 193 respondents who answered the question "What diseases or illness did you think were of particular interest to us?" $105\left(54^{\circ}{ }_{0}\right)$ realised that it was about cervical cancer and 46 $(24 \%)$ thought it was about cancer in general. Thirty respondents $\left(16^{\circ}{ }_{0}\right)$ thought that it was about gynaecological problems and 15 respondents $\left(8^{\circ}{ }_{0}\right)$ about sexually transmitted diseases. (A few cited more than one type of disease.)

Finally the questionnaire asked for general comments. One hundred and twenty three women made some comment. Of those not mentioned above, 41 respondents ( 17 cases and 24 controls) said that they were glad to have participated or hoped that they had helped, 43 made specific complimentary remarks about their interviewer, eight expressed their willingness to be contacted again, while one, although glad to have helped, now "wished to forget". Eleven respondents felt that the survey was not sufficiently wide ranging and 13 respondents asked to be informed of the findings.

\section{Discussion}

We were encouraged by the high response rate of $90^{\circ}{ }_{0}$, similar to the $80^{\circ}{ }_{0}$ of Funch and Marshall ${ }^{2}$ and $89^{\circ}{ }_{0}$ of Savitz et al. ${ }^{3}$ By sending the questionnaire one month after the last contact with the interviewer, we hoped to elicit responses that would indicate whether or not there was any lasting ill effect of inclusion in the study. Studies of responders to screening programmes have indicated that not only may a false positive result generate lasting anxiety ${ }^{4}$ but that attendance at a screening clinic per se may have a negative psychological effect detectable only several months after screening, ${ }^{5}$ and this is precisely the sort of effect that we wished to investigate. Those reminded by telephone after initially failing to return the questionnaire were nearly always apologetic and ready to help, saying that they had been busy or had forgotten. The non-responders inevitably included a few whom we were unable to trace, and who had probably moved, and some who said they had returned or would return the questionnaire, but it failed to arrive. None of the latter group expressed any concern about the interview. Three cases refused outright to complete the questionnaire. It might be argued that the $10^{\circ}{ }_{0}$ of non-responders were those least glad to have taken part in the interview, but on the other hand those who had strong negative reactions might have used this opportunity to inform the researchers of their feelings. An analysis of responders to the survey at the first or second round suggests few differences. The 45 women who responded at the second round were slightly more likely to have found the original interview inconvenient $\left(9^{\circ}{ }_{0}\right.$ versus $\left.3^{\circ}{ }_{0}\right)$ and to wish that they might curtail it $\left(9^{\circ}{ }_{0}\right.$ versus $\left.3^{\circ}{ }_{0}\right)$, and fewer of them had been contacted about it by their general practitioner $\left(18^{\circ}{ }_{0}\right.$ versus $\left.29^{\circ}{ }_{0}\right)$. However the proportions feeling glad that they had taken part were very similar $\left(97^{\circ}{ }_{0}\right.$ and $\left.98^{\circ}{ }_{0}\right)$. There were few statistically significant differences in response between cases and controls, although numbers are insufficient to demonstrate a difference of less than about $10^{\circ}$. with $50^{\circ}$ o power.

In spite of the sensitive nature of the questions in the original study, $97^{\circ}$ of respondents were happy to have participated, similar to the $90^{\circ}$ of Savitz et $\mathrm{al}^{3}$ and the $84^{\circ}{ }_{0}$ of Funch and Marshall. ${ }^{2}$ The overwhelming incentive to participate was the perceived importance of the study $\left(98^{\circ}{ }_{0}\right)$; this compares with $91^{\circ}{ }_{0}$ in the study of Savitz et al. ${ }^{3}$ 
Understandably a recent health experience was more important to the cases; it could be argued that if cancer had been acknowledged as the disease in question, the study would have been seen to be of even greater importance because cancer is universally recognised and has touched almost every family, however remotely. Walter $e t$ $a l^{6}$ found an improved response rate when cancer was mentioned in an initial contact letter. Most respondents $(78 \%)$ realised that cancer was the purpose of our study, and this clearly did not deter them from participating.

The major factor causing worry about participation was the disclosure of personal information, followed, but to a much lesser degree, by having a stranger in the home. The questions on sexual partners clearly caused most concern; it must be borne in mind that the original interview was particularly probing on sensitive and private aspects of the interviewee's life, but adverse reactions appeared to be either transitory or relatively limited, and did not affect the overall satisfaction or benefit experienced by the participants in retrospect.

The interview itself is obviously the most important aspect of the study to the interviewee; it therefore follows that the calibre of the interviewers is of paramount importance. They must appear sympathetic and reassuring yet highly professional. There were many spontaneous compliments about the interviewers, and only one adverse comment. The majority of respondents found it easier than expected to talk to them, which underlines the importance of interviewing technique.

The role of general practitioners can be of great importance when they are sympathetic to the aims of the study. They can provide reassurance to their patients, confirming that the researchers are genuine and well regarded, and that the research topic has their blessing, while in no way coercing their patients to participate. Seventy seven per cent of respondents were glad that their general practitioner allowed us to contact them, but $47 \%$ would have agreed without general practitioner consent; this confirms the findings of Funch and
Marshall, ${ }^{2}$ and Boring et al. ${ }^{7}$ Unfortunately, there were a few instances when a general practitioner denied knowledge of the study to his or her patient even though signed consent for that patient to be contacted had been given. Rothman ${ }^{8}$ has suggested that while physicians should consider their patients' privacy, they should also allow them the privilege of contributing to research directed at the prevention and control of disease. Our results would indicate that our interviewees were aware of that privilege. The very real danger has been pointed out that "constraints imposed will deprive society of the benefits research can yield". 9 Constraints imposed by ethics committees, and refusal by individual doctors to allow patients to choose for themselves whether to participate in cancer surveys, should be based on knowledge of what the risks are likely to be. Our findings and those of others ${ }^{2} 3$ are reassuring; research involving well conducted interviews can be carried out without causing lasting psychological harm.

We thank all the interviewees who participated in the post-interview survey so willingly. The manuscript was prepared by Sybil Farrell, Sandra McVeigh, and Ruth Gell. The cervical cancer case-control study on which this survey was based was funded by the Cancer Research Campaign and Medical Research Council through their support for the Institute of Cancer Research, and by the Imperial Cancer Research Fund.

1 Pearce JMS. Ethics committees. Lancet 1986; i: 1156.

2 Funch DP, Marshall JR. Patient attitudes following participation in a health outcome survey. Am $尹$ Public participation in a health

3 Savitz DA, Hamman RF, Grace C, Stroo K. Respondents' attitudes regarding participation in an epidemiological study. Am F Epidemiol 1986; 123: 362-6.

4 Marteau TM. Psychological costs of screening. BMF 1989; 299: 527.

5 Stoate HG. Can health screening damage your health? $f R$ Coll Gen Pract 1989; 39: 193-5.

6 Walter SD, Marrett LD, Mishkel N. Effect of contact lette on control response rates in cancer studies. Am $\mathcal{F}$ Epidemio 1988; 127: $691-4$.

7 Boring CC, Brockman E, Causey N, Gregory HR, Greenberg RS. Patient attitudes toward physician consent in
epidemiologic research. Am 尹 Public Health 1984; 74: $1406-8$.

8 Rothman KJ. The epidemiologist's lament. Am $f$ Public Health 1981; 71: 1309-11.

9 Hershey N. Putting the lamentations of epidemiologists in perspective. Am $\Im$ Public Health 1982; 72: 1155-7. 